\title{
C-42 GEOPHYSICAL CHARACTERISATION OF THE SIMIAN DISCOVERY, WEST DELTA DEEP MARINE CONCESSION, NILE DELTA, EGYPT
}

ANDY SHARP' ${ }^{1}$ ANDY SAMUEL ${ }^{1}$ and FRANCESCO FEDERICI ${ }^{2}$ 'BG Egypt, 23 Road 216 Digla, Maadi, Cairo, Egypt

${ }^{2} E D I S O N$ GAS

\begin{abstract}
Simian is a deep water (300-1500m depth) discovery located $75 \mathrm{~km}$ north-east of Alexandria in the western part of the Offshore Nile Delta. The discovery well, Simian-1 was drilled in 1999 and a second well, Simian-2 has been drilled in 2000. Both of these wells were located based on seismic data from a c. $1500 \mathrm{sq} . \mathrm{km}$. 3D seismic survey which was acquired in 1997/8. The seismic response of the Simian Plio-Pleistocene gas saturated sands is a 'soft' seismic kick which stands out remarkably from the background shales and water saturated sands. Careful and dense (every other line) seismic picking of top and base reservoir has enabled the production of a variety of geophysical attributes over the Simian discovery from both conventional and continuity seismic volumes. An example Average Absolute Amplitude (AAA) between top and base Simian reservoir is shown in Fig 1. A continuity slice from $300 \mathrm{~ms}$ below and parallel to water bottom is shown in Fig 2. The continuity slice exhibits a variety of features typical of the WDDM concession, these include a gas chimney, soft sediment deformation and faulting. Both of these figures demonstrate the excellent quality of the 3D seismic data acquired to date within the WDDM concession. A brief overview of the processing sequence used to obtain these data will be described.
\end{abstract}

Depth conversion for the Simian discovery is critical given the variability of the water depths over the discovery, the elongate nature of the prospect and the relatively low relief. A variety of depth conversion methodologies have been used as sensitivity studies. These include polynomial, stacking velocity and 'bottom-up' gas water contact (GWC) based approaches. The present interpretation is that the Simian discovery is structurally controlled along axis and laterally stratigraphically trapped by the shale dominated channel margins. This interpretation is supported by the presence of GWC's at each end of the channel along strike.

For future 3D characterisation of the reservoir, well ties are critical. Good results have been obtained by using a combination of logging while drilling, corrected for invasion wireline logs and careful checkshot editing. Detailed reprocessing of selected sail lines adjacent to the wells from the 3D volumes has also been undertaken to provide further insights into well ties. Example seismic to well ties from the two wells drilled to date and both $2 \mathrm{D}$ and $3 \mathrm{D}$ seismic lines will be displayed and discussed. 


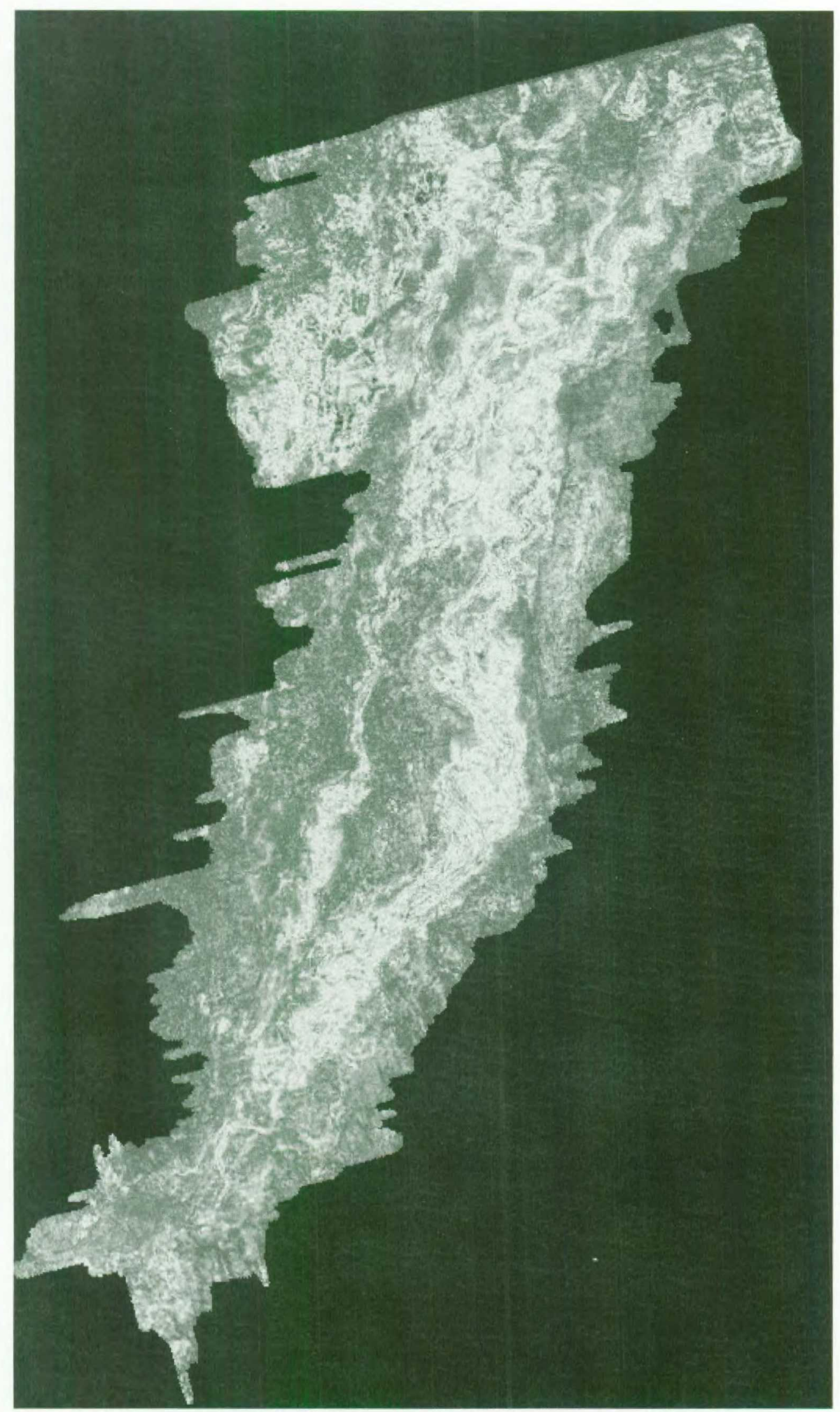

Fig 1. Average Absolute Amplitude (AAA) between top and base Simian seismic picks BG Egypt 


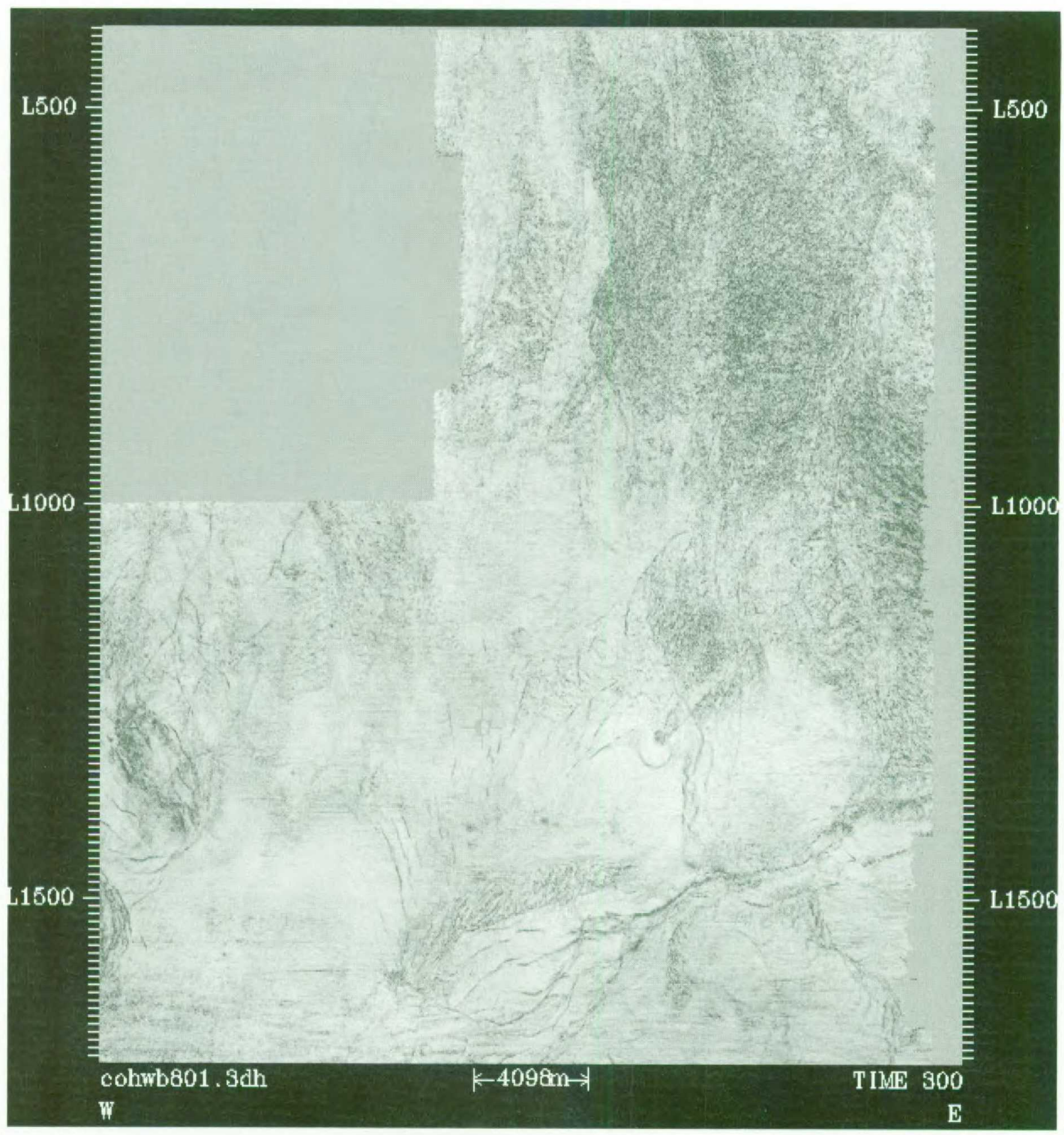

Fig 2. Continuity slice parallel and $300 \mathrm{~ms}$ below water bottom over the Simian area.

BG Egypt 